\title{
Social Costs of Setting High Aspirations in Competitive Negotiation
}

\section{Citation}

Lai, Lei. No date. Social Costs of Setting High Aspirations in Competitive Negotiation. Doctoral dissertation, Harvard University.

\section{Published Version}

doi:10.1111/ncmr.12000

\section{Permanent link}

http://nrs.harvard.edu/urn-3:HUL.InstRepos:37927289

\section{Terms of Use}

This article was downloaded from Harvard University's DASH repository, and is made available under the terms and conditions applicable to Other Posted Material, as set forth at http:// nrs.harvard.edu/urn-3:HUL.InstRepos:dash.current.terms-of-use\#LAA

\section{Share Your Story}

The Harvard community has made this article openly available.

Please share how this access benefits you. Submit a story.

\section{Accessibility}


Running head: SOCIAL COSTS OF SETTING HIGH ASPIRATIONS

Social Costs of Setting High Aspirations in Competitive Negotiation

Keywords: negotiation, aspirations, future cooperation 


\begin{abstract}
This paper explores the implications of a negotiator setting high aspirations on the counterpart's assessments of the negotiator and future cooperation toward the negotiator. Participants were 134 undergraduates acting as buyers or sellers in a single-issue price negotiation. Buyers received instructions to set more or less ambitious aspirations. Buyers who set more ambitious aspirations achieved better economic outcomes. However, sellers paired with buyers setting more ambitious aspirations found their buyers to be less likeable, expressed less willingness to cooperate with them in the future, and behaved less generously toward them in a post-negotiation dictator game. The perceived likeability of the buyer explained why the sellers were less willing to cooperate in the future with buyers who had set more ambitious aspirations. This research contributes to the understanding of the downside of setting high aspirations in a competitive negotiation and provides implications on balancing one-time economic gain with future social loss.
\end{abstract}


Social Costs of Setting High Aspirations in Competitive Negotiation

One could read a review of the goal-setting literature and walk away thinking of high aspirations like a motivational vitamin for individual achievement. Ambitious goals help to focus the mind, energize physical efforts, enhance perseverance and ultimately raise performance, and these benefits have been demonstrated across a diverse range of domains from test-taking to corporate cost-savings to logging rates (Locke \& Latham, 1990 \& 2002).

Within the realm of negotiation research, it has been shown that parties who set relatively high aspirations tend to claim higher individual payoffs (Galinsky, Mussweiler, \& Medvec, 2002; Hamner \& Harnett, 1975; Neale \& Bazerman, 1985; Siegel \& Fouraker, 1960; White \& Neale, 1994) and to reach more efficient agreements in negotiations with integrative potential (Ben-Yoav \& Pruitt, 1984; Kimmel, Pruitt, Magenau, Konar-Goldband, \& Carnevale, 1980; Pruitt, 1998; cf. Polzer \& Neale, 1995). However, there is a downside that has been identified: While negotiators with high aspirations do tend to outperform those with less ambitious aims (Zetik \& Stuhlmacher, 2002), they are also more likely to incur costly delays in achieving agreement (Neale \& Bazerman, 1985), run a greater risk of negotiating impasse (Babcock \& Loewenstein, 1997; Ben-Yoav \& Pruitt, 1984; Huber \& Neale, 1987; White \& Neale, 1994), and may be less satisfied with their negotiation outcomes (Galinsky et al., 2002).

This study tests another potential negative aspect of negotiators setting high aspirations in competitive negotiations - namely the impressions that negotiating counterparts form of them and the impact of those impressions on the counterparts' behavior towards them in the future. More specifically, we investigate the effect of negotiators setting relatively ambitious aspirations on their likeability, their negotiating counterparts' willingness to cooperate with them in the future (a self-report intention measure), and on their counterparts' generosity toward them (an 
actual behavioral measure). This experimental study contributes to the recent literature in negotiation that broadens the focus of research beyond studying instrumental economic outcomes to understanding the implications of negotiation on the relationships with counterparts (Curhan, Elfenbein, \& Xu, 2006). At a practical level, our aim is to help negotiators better understand the connections between goals, economic outcomes, and relationships with negotiation counterparts.

In this study, we use a single-issue, competitive bargaining situation in which the time costs of negotiation are trivial and there is little risk of bargaining impasse. Previous research has shown in this type of setting that negotiators with ambitious aspirations will obtain more favorable agreements than negotiators with more modest aspirations (Galinsky et al., 2002; Hamner \& Harnett, 1975; Neale \& Bazerman, 1985; Siegel \& Fouraker, 1960; White \& Neale, 1994). This literature forms the basis of Hypothesis 1.

Hypothesis 1: Negotiators who set more ambitious aspirations will achieve better economic outcomes than negotiators who set less ambitious aspirations.

In a single-issue negotiation, a negotiator's individual economic payoff is, by definition, in conflict with the economic payoff of their negotiating counterpart (Lax \& Sebenius, 1986). Negotiators who strive for high aspirations may risk having their negotiating counterparts form negative impressions of them.

There are two mechanisms by which a negotiator who sets more ambitious goals could lead to being less liked by the negotiation counterpart than a negotiator who sets less ambitious goals. First, in single-issue competitive negotiations, more economic value for one party amounts to less economic value for the other. If Hypothesis 1 is supported, when the negotiator sets a more ambitious goal and receives a larger economic payoff, the counterpart will obtain a 
lower economic payoff. Based on the dynamic model of affect in dyadic negotiation proposed by Barry and Oliver (1996) in which they suggested that one's economic payoff may influence affective consequences of a negotiation (including perceptions about the counterpart), we argue that obtaining a lower economic payoff by the counterpart could lead to negative affect for the counterpart that could carry over to how much they like the ambitious negotiator.

Second, a negotiator's behavior can also affect counterparts' assessments of them. Having more ambitious aspirations in competitive negotiations can lead negotiators to adopt more aggressive negotiation behaviors. Theses bargaining behaviors include making extreme offers, resisting concessions, degrading the value that the other side brings to the negotiation table (for example by denigrating the value of the product the counterpart is selling), and putting pressure on the other side to accept their offer. These behaviors are typically seen in a nonpositive light by the counterpart because they tend to fall along the blurring line of ethically questionable bargaining behaviors (Lewicki \& Robinson, 1998), and can therefore affect how much they like the negotiator who engages in these behaviors.

Previous research has provided evidence consistent with this hypothesis. Morris, Larrick and Su (1999), for instance, showed that MBAs negotiating as job candidates in a compensation simulation were judged to be significantly more disagreeable by their counterparts (playing the recruiters) when they were randomly assigned high (v. low) outside offers to match in the negotiation. Morris and colleagues' research illuminates a point that is often neglected in negotiation research: "negotiations have not only an economic but also a social outcome" (Morris et al., 1999, p. 66). We hypothesize, therefore, that the counterparts of negotiators who set more ambitious aspirations will perceive them to be less likeable than negotiators who set more modest aspirations. 
Hypothesis 2: The counterparts of negotiators who set more (vs. less) ambitious aspirations will perceive them to be less likeable.

Several studies have shown that outcomes and behavior in one negotiation can impact the negotiators' willingness to cooperate with each other in the future. In the Morris et al. (1999) paper, recruiters who negotiated with candidates with high (v. low) outside offers reported having less confidence that they would be able to resolve future conflicts directly through negotiation with their counterparts. Recruiters were also significantly more likely to recommend candidates assigned high (v. low) outside offers for an "external bargaining role" within the company, potentially pigeonholing them into positions focused on "one-time transactions" and requiring "assertiveness and competitiveness" as opposed to relationship management skills ( $\mathrm{p}$. 59). In addition, studying negotiations in the MBA classroom (Curhan et al., 2006) found that the outcome of one negotiation can have large consequences on the willingness to negotiate with the counterpart in the future, to want to cooperate with them in other endeavors, and on a behavioral measure of choosing them as a future teammate. We therefore predict that the counterparts of negotiators with more ambitious aspirations will express less willingness to cooperate with them in the future.

Hypothesis 3a: The counterparts of negotiators who set more (vs. less) ambitious aspirations will be less willing to cooperate with them in the future.

We propose that this diminished willingness for future cooperation with negotiators with ambitious aspirations will occur because counterparts like these high aspiring negotiators less than the low aspiring negotiators. In the Morris et al. paper (1999) discussed above, the reason that recruiters of candidates with higher outside offers were less confident about their ability to resolve future conflicts with their candidates was because they viewed their counterparts with 
high outside offers to be significantly more disagreeable than those with low outside offers. This finding is supported by the literature on social influence that suggests a strong and positive link between liking and favorable actions toward the liked individual (for a review, see Cialdini \& Trost, 1998). Individuals are more likely to attend the needs of those whom they like than those whom they dislike. Liking may lead to cooperative behavior and cooperation in turn may further increase positive feelings (such as liking) (Cook, 1990). Putting these literatures together we predict that the counterparts of negotiators who set more (vs. less) ambitious aspirations will perceive them to be less likeable and that this lower likeability will lead to a lower willingness for future cooperation.

Hypothesis $3 b$ : The counterparts' perceived likeability of the negotiators will mediate the effect of negotiators' setting more (vs. less) ambitious aspirations on the counterparts' willingness for future cooperation.

Beyond the self-report perceptional measures, we test further whether the counterparts' expressed willingness for cooperation will be consistent with actual behavior in an individual decision-making exercise in which the counterpart is given an opportunity to act generously toward the negotiator. We predict that the counterparts of negotiators with more (vs. less) ambitious aspirations will also behave less generously toward them, and that the counterparts' perceptions of how likeable the negotiator is will mediate this effect.

Hypothesis 4a: The counterparts of negotiators who set more (vs. less) ambitious aspirations will behave less generously toward them.

Hypothesis 4b: The counterparts' perceived likeability of the negotiators will mediate the effect of negotiators' setting more (vs. less) ambitious aspirations on the counterparts' generosity toward them. 


\section{Experiment}

We randomly assigned participants to roles in a single-issue, buyer-seller negotiation and paid them based on how much of the surplus they negotiated (i.e., the difference between their reservation value and the agreement price). We manipulated whether the buyers set a more or less ambitious target price, which we correspondingly refer to as "high" vs. "low" aspirations. Immediately following the negotiation, participants completed a survey regarding their offer behavior, negotiation outcomes, their impression of their negotiating counterparts, and their willingness for future cooperation with their negotiating counterparts. After completing the postnegotiation survey, we collected a behavioral measure of the sellers' future generosity toward their negotiating counterparts using a version of the dictator game.

\section{Participants}

A total of 134 individuals (67 negotiating pairs) participated in this study in return for a show-up fee of $\$ 10$ plus additional money that could be earned during the experiment. Participants were undergraduate students who signed up online to participate in a decisionmaking study at a local-area university. The average age of the participants was 20 years. As explained below, we removed five pairs from the analysis for failing to follow the negotiating instructions.

\section{Procedure}

After obtaining the participants' consent to participate, the experimenters randomly distributed a multi-packet set of experimental materials labeled with participant numbers. The experimenters instructed the participants to open and review the first packet, which contained their confidential instructions for the negotiation and a short pretest to confirm their understanding of their negotiating instructions and how they would be paid based on their 
performance in the negotiation. The negotiation scenario involved a supplier (seller) and a motorcycle manufacturer (buyer) negotiating over a single issue, the price per unit on a special order of headlights (an adapted version of Sebenius, 1996). Participants had 15 minutes to read their confidential instructions and to complete the pretest.

The confidential instructions informed each party of their own but not the other side's reservation value and provided no other indication of the size of the bargaining zone. We embedded the experimental manipulations in the buyers' confidential instructions. We held the buyer's and seller's reservation values constant across conditions. The seller's reservation price was $\$ 17 /$ unit. The buyer's reservation price was $\$ 26 /$ unit.

In the high aspiration condition, the buyers' target purchase price was $\$ 19 /$ unit. In the low aspiration condition, the buyers' target purchase price was $\$ 24 /$ unit. Note that both target prices were within the zone of possible agreements. In the confidential instructions for the buyers, we informed them that they would receive a bonus payment of $\$ 3$ if they negotiated an agreement that was better than their assigned target price. We also suggested that they open the negotiation with a starting offer that was $\$ 3$ less than their target price. In this way, we minimized the variance in the buyers' bargaining behavior within conditions in a naturalistic way, rather than relying on a confederate or computerized opponent which would introduce artificiality into the interaction and diminish the applied implications of the findings by testing only one specific script for acting out each condition. The sellers' confidential instructions were held constant across conditions, and instructed the sellers to allow the buyer to make the first offer.

Once the experimenters had collected all of the pretests and checked them for errors, they paired the participants up by participant number to negotiate in different sections of a large 
lecture hall. Experimenters gave participants a maximum of ten minutes to negotiate, and instructed participants to return immediately to their original seats once they had completed the negotiation to start working on the next packet. The next packet contained a post-negotiation survey with questions about their offer behavior, the outcome of their negotiation, their impressions of the negotiating counterparts, and their willingness to cooperate with their negotiating counterparts in the future.

After collecting the post-negotiation surveys, the experimenters explained that the final packet contained an individual decision-making exercise, in which the participants would either play the role of decision maker or decision receiver. (The individual decision-making exercise was a version of the game known to researchers as the "dictator game.") All of the decision makers (decision receivers) were sellers (buyers) in the negotiation, but the experimenters did not reveal this to the participants. The final packet informed decision makers (sellers) that they had $\$ 10$ to allocate and described two different allocation scenarios. In Scenario \#1, the decision maker (seller) would split the $\$ 10$ with another anonymous and randomly assigned participant. In Scenario $\# 2$, the decision maker (seller) would split the $\$ 10$ with the person with whom they had just negotiated. To protect the anonymity of the decision makers, the instructions explained that the experimenters would pick one of the two scenarios to pay out at the end of the experimental session and that the decision receivers would not know which scenario the experimenters had picked. (The experimenters always made the allocation based on Scenario \#1.) The instructions for the decision receivers (buyers) explained that they had been paired with an anonymous decision maker (seller) who would decide how much of a total of $\$ 10$ to allocate to them. Decision receivers (buyers) then completed a set of hypothetical questions about much they expected to receive from their seller. 


\section{Measures}

As a check on the aspiration manipulation, participants reported who made the first offer and for how much. Participants also reported whether they had reached agreement and, if so, at what price per unit. We used an adapted version of Rudman and Glick's (1999) Social Skills Index as a measure of the negotiators' impressions of the likeability of their counterpart. Participants rated on a scale of 1-7 how much each of the following 11 words characterized the impression created by their negotiating partner: fair, friendly, good listener, helpful, kind, likeable, popular, sensitive to the needs of others, sincere, supportive and warm. As a measure of their willingness for future cooperation, the participants indicated on a scale of 1-7 how inclined they would be to do this person a favor, to have this person on their team for a class project, to recommend this person for a job, and to include this person in social activities with other classmates.

The decision makers in the dictator game (who were the sellers in the negotiation) reported how much they were willing to allocate of their $\$ 10$ to another randomly assigned, anonymous study participant (Scenario \#1) and how much they were willing to allocate of their $\$ 10$ to the person with whom they had just negotiated (Scenario \#2). This latter measure provided a behavioral indication of the sellers' generosity toward their negotiating counterpart. Decision receivers (who were buyers in the negotiation) reported how much they thought the person with whom they had just negotiated would give to them.

\section{Results}

All of the negotiating pairs reached agreement. We removed five cases from the analysis because the buyer had not made the first offer the way as they were instructed to make. There 
were 37 dyads in the high aspiration condition and 25 in the low aspiration condition. Table 1 displays descriptive statistics.

\section{Economic Outcomes}

Consistent with expectations, buyers with high (vs. low) aspirations negotiated significantly lower/better prices for themselves, $t(60)=6.09, p<.001$. Specifically, buyers with high (vs. low) aspirations paid approximately $10 \%$ less per unit, $M_{\text {Difference }}=\$ 2.43$, supporting H1.

\section{Social Outcomes}

Likeability. We combined the 11 impression items into a mean composite indicator of "likeability" ( $\alpha=.95$ for sellers, $\alpha=.93$ for buyers). The sellers found the buyers with high (vs. low) aspirations to be significantly less likeable, $M_{\text {Difference }}=1.03, t(60)=3.72, p<.001$, supporting H2. Mirroring the sellers' reported impressions, buyers with high (vs. low) aspirations also found their negotiating counterparts to be significantly less likeable, $M_{\text {Difference }}=$ $0.58, t(60)=2.29, p=.03$.

Willingness for Future Cooperation. We combined the four indicators of willingness for future cooperation into mean composite indicators $(\alpha=.91$ for sellers, $\alpha=.83$ for buyers). As predicted in $\mathrm{H} 3 \mathrm{a}$, sellers were significantly less motivated toward future cooperation with buyers with high (vs. low) aspirations, $M_{\text {Difference }}=0.66, t(60)=2.21, p=.03$. On the other hand, for buyers, whether they had set high or low aspirations had no significant effect on their willingness for future cooperation with the sellers, $M_{\text {Difference }}=0.06, t(60)=0.22, p=.83$.

Generosity. As shown in Table 1, sellers were significantly less generous in the dictator game toward buyers with high (vs. low) aspirations, $M_{\text {Difference }}=1.30, t(60)=2.72, p<.01$, supporting H4a. When the sellers negotiated with a buyer with high aspirations, the modal 
outcome was zero: $41 \%$ allocated none of the $\$ 10$ to their counterparts. Only $8 \%$ of sellers negotiating with high aspiration buyers allocated $\$ 5$ to the buyers. When the sellers negotiated with buyers who set low aspirations, the modal outcome was an even split: $36 \%$ allocated $\$ 5$ of the $\$ 10$ dollars to their counterparts. (See Figure 1 for histograms of the sellers' generosity to the buyers by aspiration condition and of the buyers' expected generosity from the sellers by aspiration condition.) The sellers' generosity toward a randomly assigned, anonymous other participant was significantly correlated with their generosity toward their negotiating counterparts $(r=.58, p<.001)$, but the level of aspiration set by the buyer did not have a statistically significant effect on how much the sellers' allocated to a randomly assigned, anonymous other participant, $M_{\text {Difference }}=0.77, t(41)=1.71, p=.10$.

The buyers appeared blind to the effect of the negotiation on their counterparts' likely generosity toward them. Buyers who had set high aspirations expected as much generosity from their negotiating counterparts as did buyers who had set low aspirations, $M_{\text {Difference }}=-\$ 0.36, t(60)$ $=-0.62, p=.54$. Indeed, the lower the price that the buyers negotiated, the more generous they presumed the seller would be toward them $(r=-.43, p<.01)$. The modal expectation of buyers who had set high aspirations was that the sellers would allocate them half of the $\$ 10$, whereas the modal response by their counterparts was to give to them nothing.

\section{Mediation Analysis}

Table 2 summarizes the results of regressions used in the mediation analyses. As predicted, the perceived likeability of the buyer mediated the effect of the aspiration manipulation on the sellers' willingness for future cooperation with the buyer, Sobel $z=3.24, p$ $=.001$ (Sobel, 1982), supporting H3b. As can be seen by comparing the regression models in the first and third columns in the top half of Table 2, the effect of the manipulation declines to 
insignificance $(\beta=.06, t=0.25, p=.80)$ after controlling for how likeable the seller perceived the buyer to be. The perceived likeability of the buyer remains a significant predictor of the sellers' willingness for future cooperation $(\beta=.70, t=6.63, p<.001)$.

As shown in the second column of the bottom half of Table 2, the seller's assessment of the buyer's likeability was a significant predictor of the seller's generosity toward the buyer, $\beta=$ $.51, t=2.50, p=.02$. Sellers allocated more money to buyers whom they perceived to be more likable. However, the perceived likeability of the buyers was not a full mediator of the effect of the aspiration manipulation on the sellers' generosity, Sobel $z=1.39, p=.16$ (Sobel, 1982), not supporting H4b.

\section{Discussion}

This study finds that negotiators with more ambitious aspirations claimed a significantly greater percentage of the surplus, which replicates the well-established benefits of high aspirations in terms of the economic outcomes of competitive negotiations. However, our analyses of the social outcomes of this negotiation revealed a more complex picture of the potential implications of ambitious aspirations on competitive negotiation performance than is generally discussed.

Setting more ambitious aspirations reduced the perceived likeability of the negotiator. The counterparts of negotiators who set more ambitious aspirations were significantly less inclined to cooperate with them in the future and behaved significantly less generously toward them in a post-negotiation allocation decision. The modal response of the counterparts of negotiators who set more ambitious prices was to share nothing with them, whereas the modal response of the counterparts of negotiators who set less ambitious target prices was to allocate them half of the pie. The perceived likeability of the negotiator explained the effect of setting 
ambitious aspirations on the counterparts' willingness for future cooperation. Perceived likeability was significantly, positively correlated with the generosity of the counterparts' behavior in the post-negotiation allocation decision, but it did not mediate the effect of setting ambitious aspirations. This suggests that our measure of likeability did not fully capture why counterparts of more ambitious negotiators were less generous. It is possible that the postnegotiation dictator game we used focuses the decision maker on issues of distributive fairness rather than liking and may be more linked to the lower economic payoffs they received in the negotiation than on their assessments of their counterpart. Deeper investigation of the impact of the perceptions of fairness and likeability is warranted to understand how behavior at the bargaining table may influence the potential for future relations both economically and socially. Another feature of this study that is worth noting is that we implemented both a hypothetical intention measure (i.e., willingness to cooperate in the future) and actual behavioral measure (the dictator game following the negotiation) of future cooperation. Both measures yield a consistent finding that setting more ambitious aspirations reduces the likelihood of future cooperation from the negotiating partner. This consistency indicates the robustness of our results and enhances the validity of the findings.

Research has shown that negotiators are not immune to the fundamental attribution error (Ross \& Nisbett, 1991), making general, dispositional attributions for behavior observed within specific negotiating situations (Morris et al., 1999). These attributions could be particularly virulent, if the impressions formed during negotiation become the basis for unwanted reputations or self-fulfilling, interpersonal expectancies (Rosenthal, 1994). There is some evidence that having a reputation as a competitive negotiator serves one well in terms of negotiated payoff in distributive bargaining by making one's negotiating partner meeker (Diekmann, Tenbrunsel, \& 
Galinsky, 2003). However, research shows that unwittingly entering a negotiation with integrative potential with a distributive reputation actually undermines individual performance (Tinsley, O'Connor, \& Sullivan, 2002). If negotiators are unaware of the impressions that they are making, they may not realize the full costs or benefits of their actions or be able to mitigate false attributions. More insidiously, they may actually end up fulfilling the expectations of others and developing a distorted self-concept as a negotiator. Research by Diekmann et al. (2003) showed that negotiators who expected relatively competitive counterparts actually induced their counterparts to develop more competitive self-concepts.

\section{Limitations}

Within the context of this particular negotiation, it is unclear whether the additional money that the negotiators with more ambitious aspirations earned would have outweighed in their own minds the relatively negative impressions they made on their negotiating partners. Certainly, there are negotiating contexts, such as one-time car or real-estate sales, in which parties are likely to perceive little harm in alienating their interlocutor for the sake of getting the best possible deal. Yet, even car salespeople should consider whether they are negotiating with a potential repeat customer or someone who might refer business to them. Arguably, most negotiations carry at least some potential for future cooperation. In many negotiating situations, reaching agreement becomes the first stage of negotiation in an ongoing working relationship, and the social outcomes of initial deal-making could have lasting implications for the quality of that working relationship (Barry \& Oliver 1996; Fortgang, Lax, \& Sebenius, 2003; Gray, 1989).

Another limitation of the current research is the strictness with which we conducted the aspiration manipulations. By controlling the negotiators' offer behavior and providing extra motivation for them to reach the target price that we assigned, we were able to compare the 
social and economic effects of setting more vs. less ambitious aspirations. The disadvantage of this experimental design is that we cannot disentangle the effects of making an ambitious first offer from the simple effect of being assigned high vs. low aspirations, though past research suggests that aspirations and first offers are highly correlated (e.g., Buelens \& Van Poucke, 2004; Van Poucke \& Buelens, 2002). It is noteworthy, however, that the agreement price for which the participants in the high aspiration condition strove was not outrageous $(77 \%$ of bargaining surplus), and it still reduced the potential for future cooperation. Therefore, while the behaviors were strictly controlled, this was a relatively conservative test of the effects of setting ambitious aspirations on the social outcomes of negotiation.

Another limitation is regarding the duration of the effect of setting ambitious aspirations on generosity. The dictator game that measures behavioral generosity toward the negotiators with high vs. low aspirations took place right after the negotiation simulation. Arguably, we have no way to test how much longer this effect of aspiration manipulation on generosity would last and this temporal component needs to be investigated further. In addition, our behavioral measure of social costs was in the form of a dictator game, not a subsequent negotiation task, which limits the practical implications on how the outcome of one negotiation may spillover to affect cooperation in another future negotiation.

\section{Contributions}

The current research contributes to both the literatures on goal-setting and negotiation in the context of future relationships. Researchers have studied the effects of goal-setting on individual performance for decades, but relatively little attention has been paid to the social implications of setting high aims for individual performance in an interactive and interdependent context such as negotiation. The findings of our research demonstrate that there may be 
substantial trade-offs between the individual performance gains and the tax that striving for those gains levies on the social interaction. Future research on goal-setting and task performance should delve more deeply into the implications of high goals for individual performance in domains in which there are both structural limits and social costs to individual achievement.

In the negotiation field, we tend to think of and operationalize negotiation performance in terms of individual and joint payoffs, which only takes into account the one-time economic outcomes of negotiations. The social outcomes of negotiations may have more far-reaching implications than one's individual payoff from a single negotiation (Curhan, Elfenbein \& Kilduff, 2009). The research on negotiation subjective value (Curhan et al., 2006) echoes our concerns by mapping out multiple dimensions of negotiated outcomes that are beyond economic outcome. Our study of social costs of setting high aspiration contributes to the understanding of how the feelings about the relationship with the negotiating counterpart (as a dimension of subjective value of a negotiation outcome) may affect them working together in the future. Putting together, when we consider the implications of goal-setting for negotiation performance, we should take into account and advise negotiators to balance the social as well as economic implications of striving for ambitious individual payoffs. These potential social costs in the context of future relationships have been largely neglected in the negotiation literature, and we do a disservice to those to whom we offer prescriptive advice if we fail ourselves to think beyond the negotiating table. 


\section{References}

Babcock, L., \& Loewenstein, G. (1997). Explaining bargaining impasse: The role of self-serving biases. Journal of Economic Perspectives, 11, 109-126.

Barry, B., \& Oliver, R. L. (1996). Affect in dyadic negotiation: A model and propositions. Organizational Behavior and Human Decision Processes, 67, 127-143.

Ben-Yoav, O., \& Pruitt, D. G. (1984). Resistance to yielding and the expectation of cooperative future interaction in negotiation. Journal of Experimental Social Psychology, 20, 323335.

Buelens, M., \& Van Poucke, D. (2004). Determinants of a negotiator's initial opening offer. Journal of Business and Psychology, 19, 23-35.

Cialdini, R. B., \& Trost, M. R. (1998). Social influence: Social norms, conformity, and compliance. In D. T. Gilbert, S. Fiske and G. Lindsey (eds.), The handbook of social psychology (4th ed). Boston: McGraw-Hill.

Cook, S. W. (1990). Toward a psychology of improving justice. Journal of Social Issues, 46, $147-161$.

Curhan, J. R., Elfenbein, H. A., \& Kilduff, G. J. (2009). Getting off on the right foot: Subjective value versus economic value in predicting longitudinal job outcomes from job offer negotiations. Journal of Applied Psychology, 94, 524-534.

Curhan, J. R., Elfenbein, H. A., \& Xu, H. (2006). What do people value when they negotiate? Mapping the domain of subjective value in negotiation. Journal of Personality and Social Psychology, 91, 493-512. 
Diekmann, K. A., Tenbrunsel, A. E., \& Galinsky, A. D. (2003). From self-prediction to selfdefeat: Behavioral forecasting, self-fulfilling prophecies, and the effect of competitive expectations. Journal of Personality and Social Psychology, 85, 672-683.

Fortgang, R. S., Lax, D. A., \& Sebenius, J. K. (2003). Negotiating the spirit of the deal. Harvard Business Review, 81, 66-88.

Galinsky, A. D., Mussweiler, T., \& Medvec, V. H. (2002). Disconnecting outcomes and evaluations: The role of negotiator focus. Journal of Personality and Social Psychology, $83,1131-1140$.

Gray, B. (1989). Collaborating: Finding common ground for multiparty problems. San Francisco: Jossey-Bass.

Hamner, W. C., \& Harnett, D. L. (1975). The effects of information and aspiration level on bargaining behavior. Journal of Experimental Social Psychology, 11, 329-342.

Huber, V. L., \& Neale, M. A. (1987). Effects of self- and competitor goals on performance in an interdependent bargaining task. Journal of Applied Psychology, 72, 197-203.

Kimmel, M. J., Pruitt, D. G., Magenau, J. M., Konar-Goldband, E., \& Carnevale, P. J. (1980). Effects of trust, aspiration, and gender on negotiation tactics. Journal of Personality and Social Psychology, 38, 9-22.

Lax, D. A., \& Sebenius, J. K. (1986). The manager as negotiator: Bargaining for cooperation and competitive gain. New York: Free Press.

Lewicki, R. J., \& Robinson, R. J. (1998). Ethical and unethical bargaining tactics: An empirical study. Journal of Business Ethics, 17, 665-682.

Locke, E. A., \& Latham, G. P. (1990). A theory of goal setting and task performance. New York: Prentice-Hall. 
Locke, E. A., \& Latham, G. P. (2002). Building a practically useful theory of goal setting and task motivation: A 35-year odyssey. American Psychologist, 57, 705-717.

Morris, M. W., Larrick, R. P., \& Su, S. K. (1999). Misperceiving negotiation counterparts: When situationally determined bargaining behaviors are attributed to personality traits. Journal of Personality and Social Psychology, 77, 52-67.

Neale, M. A., \& Bazerman, M. H. (1985). The effects of externally set goals on reaching integrative agreements in competitive markets. Journal of Occupational Behavior, 6, 1932.

Polzer, J. T., \& Neale, M. A. (1995). Constraints or catalysts? Reexamining goal setting with the context of negotiation. Human Performance, 8, 3-26.

Pruitt, D. G. (1998). Social conflict. In D. T. Gilbert, S. Fiske and G. Lindsey (eds.), The handbook of social psychology (4th ed). Boston: McGraw-Hill.

Rosenthal, R. (1994). Interpersonal expectancy effects: A 30-year perspective. Current Directions in Psychological Science, 3, 176-179.

Ross, L., \& Nisbett, R. E. (1991). The person and the situation: Perspectives of social psychology. New York: McGraw-Hill, Inc.

Rudman, L. A., \& Glick, P. (1999). Feminized management and backlash toward agentic women: The hidden costs to women of a kinder, gentler image of middle managers. Journal of Personality and Social Psychology, 77, 1004-1010.

Sebenius, J. K. (1996). Mapletech-Yazawa (A) and (B). Boston: Harvard Business School. Siegel, S., \& Fouraker, L. E. (1960). Bargaining and group decision making: Experiments in bilateral monopoly. New York: McGraw-Hill. 
Sobel, M. E. (1982). Asymptotic intervals for indirect effects in structural equations models. In S. Leinhart (ed.), Sociological methodology. San Francisco: Jossey-Bass.

Tinsley, C. H., O'Connor, K. M., \& Sullivan, B. A. (2002). Tough guys finish last: The perils of a distributive reputation. Organizational Behavior and Human Decision Processes, 88, $621-642$.

Van Poucke, D., \& Buelens, M. (2002). Predicting the outcome of a two-party price negotiation: Contribution of reservation price, aspiration price and opening offer. Journal of Economic Psychology, 23, 67-76.

White, S. B., \& Neale, M. A. (1994). The role of negotiator aspirations and settlement expectancies in bargaining outcomes. Organizational Behavior and Human Decision Processes, 57, 303-318.

Zetik, D. C., \& Stuhlmacher, A. F. (2002). Goal setting and negotiation performance: A metaanalysis. Group Processes and Intergroup Relations, 5, 35-52. 
Table 1

Mean Differences by Aspiration Level and Correlations for Agreement Price, Perceived Likeability of Negotiating Counterpart,

Willingness for Future Cooperation, Buyers' Expected Generosity from Sellers and Sellers' Generosity toward Buyers (N = 62 dyads)

\begin{tabular}{|c|c|c|c|c|c|c|c|c|c|c|c|c|}
\hline & \multicolumn{5}{|c|}{ Mean Differences } & \multicolumn{7}{|c|}{ Pearson Correlations $(r)$} \\
\hline & \multicolumn{2}{|c|}{ Low } & \multicolumn{2}{|c|}{ High } & \multirow[b]{2}{*}{$d$} & \multirow[b]{2}{*}{ Price } & \multicolumn{3}{|c|}{ Buyer } & \multicolumn{3}{|c|}{ Seller } \\
\hline & Mean & $S D$ & Mean & $S D$ & & & Like. & $\mathrm{FC}$ & EG & Like. & $\mathrm{FC}$ & $\mathrm{G}$ \\
\hline Price & 23.24 & 0.83 & 20.81 & 1.87 & $1.58^{* * *}$ & 1.00 & & & & & & \\
\hline \multicolumn{13}{|c|}{ Buyers Reactions Towards Sellers } \\
\hline Likeability & 5.23 & 0.93 & 4.65 & 1.02 & $0.59^{*}$ & -.15 & 1.00 & & & & & \\
\hline Future Cooperation & 4.99 & 1.20 & 4.93 & 0.97 & 0.06 & .16 & $.63^{* * *}$ & 1.00 & & & & \\
\hline Expected Generosity & 2.72 & 2.11 & 3.08 & 2.36 & 0.16 & $-.43^{* *}$ & $.44^{* *}$ & .10 & 1.00 & & & \\
\hline \multicolumn{13}{|c|}{ Sellers Reactions Towards Buyers } \\
\hline Likeability & 5.41 & 0.86 & 4.38 & 1.19 & $0.96^{* * *}$ & .25 & $.28^{*}$ & .14 & .17 & 1.00 & & \\
\hline Future Cooperation & 5.47 & 0.93 & 4.81 & 1.27 & $0.57^{*}$ & .22 & .11 & .14 & .16 & $.68^{* * *}$ & 1.00 & \\
\hline Generosity & 3.08 & 1.94 & 1.78 & 1.78 & $0.85^{* *}$ & .24 & .16 & .06 & .20 & $.31^{*}$ & $.39^{*}$ & 1.00 \\
\hline
\end{tabular}

${ }^{*} p<.05{ }^{* *} p<.01{ }^{* * *} p<.001$. 
Table 2

Regressions of Sellers' Willingness for Future Cooperation with Buyers and of Sellers'

Generosity toward Buyers in the Dictator Game by Aspiration Condition and Likeability of

Buyer $(\mathrm{N}=62$ dyads $)$

Regressions of Sellers' Willingness for Future Cooperation

\begin{tabular}{lccc} 
& 1 & 2 & 3 \\
\cline { 2 - 4 } High Aspirations $^{\mathrm{a}}$ & $-.66^{*}$ & & .06 \\
Likeability of Buyer & $(.30)$ & & $(.25)$ \\
& & $.69^{* * *}$ & $.70^{* * *}$ \\
Adjusted $R^{2}$ & & $(.10)$ & $(.11)$ \\
\hline
\end{tabular}

Regressions of Sellers' Generosity toward Buyers

\begin{tabular}{lccc} 
& 1 & 2 & 3 \\
\cline { 2 - 4 } High Aspirations $^{\mathrm{a}}$ & $-1.30^{* *}$ & & -0.96 \\
& $(.48)$ & & $(.52)$ \\
Likeability of Buyer & & $0.51^{*}$ & .33 \\
Adjusted $R^{2}$ & & $(.20)$ & $(.22)$ \\
\hline
\end{tabular}

Note. The coefficients are unstandardized betas with standard errors reported below in parentheses.

${ }^{a}$ High Aspirations equals 1 if the buyer set high aspirations, 0 if not. ${ }^{*} p<.05 .{ }^{* *} p<.01 .{ }^{* * *} p<.001$. 


\section{Figure Captions}

Figure 1. Histograms of the results of dictator game, displaying the actual allocations made by the sellers to the buyers by aspiration condition and the buyers' expectations of what allocations the sellers would make by aspiration condition. 


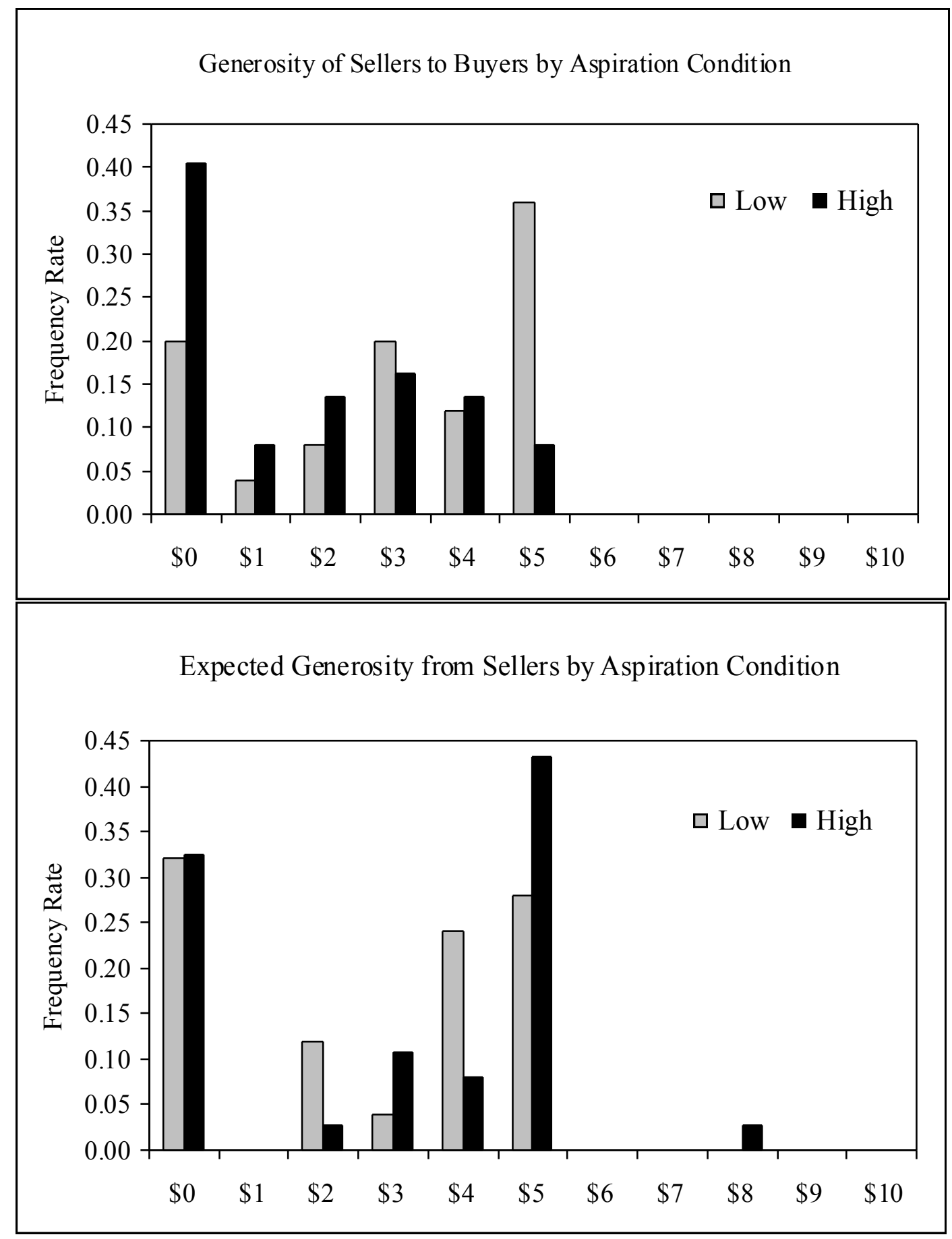

